Revta brasil. Bot., São Paulo, V.23, n.1, p.37-43, mar. 2000

\title{
Biologia floral e sistema de reprodução de Jacquemontia multiflora (Choisy) Hallier f. (Convolvulaceae) ${ }^{1}$
}

\author{
LÚCIA HELENA PIEDADE-KIILL ${ }^{2}$ e NEUSA TARODA RANGA ${ }^{3,4}$
}

(recebido em 14 de outubro de 1998; aceito em 7 de abril de 1999)

\begin{abstract}
Floral biology and reproductive system of Jacquemontia multiflora (Choisy) Hallier f. (Convolvulaceae)). The present study deals with the aspects of phenology, floral biology and reproductive system of Jacquemontia multiflora, a caatinga species at the Fazenda Catalunha, Santa Maria da Boa Vista - PE. The species is an annual liana, with cornucopia pattern of flowering. The peak of flowering occurs between the end of March begining of April at the end of the wet season. Its cymose inflorescences have the main axes elongated, exposing the flowers well out the foliage leaves. The blue flowers are shallow campanulate, scentless and producing a very low quantity of nectar. Anthesis is diurnal, the flowers begin to open at around 5:30 h, are ephemeral, lasting for about nine hours. The most frequent visitors are bees (Apidae and Halictidae). Apis mellifera and Trigona spinipes were considered the main pollinators of this species. J. multifora is facultatively autogamous, producing fruits either after self (30\%) and cross (60\%) manual pollination.
\end{abstract}

RESUMO - (Biologia floral e sistema de reprodução de Jacquemontia multiflora (Choisy) Hallier f. (Convolvulaceae)). Aspectos da fenologia, biologia da polinização e reprodução de Jacquemontia multiflora foram estudados na Fazenda Catalunha, Santa Maria da Boa Vista-PE. J. multiflora é uma liana anual, que apresenta floração do tipo cornucópia, com pico desta fenofase no bimestre março/abril, que corresponde ao final da estação chuvosa. As flores estão reunidas em cimeiras que apresentam eixo principal desenvolvido, expondo as flores acima da folhagem. As flores são raso-campanuladas, azuis, inodoras e secretam pequenas quantidades de néctar. A antese é diurna, ocorrendo por volta da 5:30 h, e a duração das flores é de aproximadamente nove horas, podendo ser consideradas como efêmeras. Abelhas Apidae e Halictidae são os visitantes mais frequentes. Apis mellifera e Trigona spinipes são consideradas como principais polinizadores desta espécie. Quanto ao sistema de reprodução J. multiflora é autógama facultativa, produzindo frutos e sementes por autopolinização manual (30\%) e também por polinização cruzada $(60 \%)$.

Key words - Floral biology, reproductive system, Jacquemontia multiflora

\section{Introdução}

O gênero Jacquemontia Choisy é composto por 100 espécies, que se distribuem principalmente pela América Tropical e Antilhas (Austin 1975). Vários representantes deste gênero e da família Convolvulaceae são considerados plantas daninhas, destacando-se entre elas Jacquemontia tamnifolia (L.) Griseb., J. densiflora Hallier, J. ferruginea

1. $\quad$ Parte da tese de doutorado de L.H. Piedade-Kiill.

2. Departamento de Botânica, Universidade Estadual de Campinas, Caixa Postal 6109, 13083-970 Campinas, SP, Brasil.

3. Departamento de Botânica, Instituto de Biociências, Letras e Ciências Exatas, Universidade Estadual Paulista “Júlio de Mesquita Filho", Caixa Postal 136, 15054-020 São José do Rio Preto, SP, Brasil.

4. Autor para correspondência: neusar@bot.ibilce. unesp.br
Choisy, J. floribunda (H.B.K.) Hallier, J. martii Choisy e $J$. vellutina Choisy que ocorrem com frequência em áreas cultivadas (Blanco 1978, Crowley \& Buchanan 1982, Kissman \& Groth 1992).

As espécies de Jacquemontia, que causam vários problemas em culturas agrícolas, apresentam caules volúveis e de rápido crescimento, formando densos emaranhados, dificultando principalmente a colheita (Groth 1991). Aspectos da produção e germinação de sementes de espécies da família Convolvulaceae têm sido alvo de estudo no campo e em laboratório, uma vez que a semente é o principal meio de reprodução dessas espécies e são encontradas com frequência nos lotes de sementes comercias de culturas agrícolas (milho, feijão), comprometendo a qualidade dos mesmos (Blanco 1978, Crowley \& Buchanan 1982, Groth 1991).

Deste modo, o presente trabalho teve como objetivo estudar a biologia floral, polinização e sistema de reprodução de Jacquemontia multiflora 
(Choisy) Hallier f. na caatinga do sertão de Pernambuco. Este trabalho visa contribuir com informações sobre as formas de reprodução e os mecanismos de polinização desta espécie, que são essenciais para a elaboração de programas de controle.

\section{Material e métodos}

O trabalho foi desenvolvido na Fazenda Catalunha ( $8^{\circ} 55^{\prime}$ S e $\left.39^{\circ} 54^{\prime} \mathrm{W}\right)$, localizada no município de Santa Maria da Boa Vista, Pernambuco. Esta fazenda ocupa uma área total de 6.934,7 ha, dos quais aproximadamente 1.400 ha são usados na fruticultura irrigada, e o restante é recoberto com vegetação nativa. A vegetação dominante na área é do tipo caatinga hiperxerófila, com espécies espinhosas (caule e folhas) das famílias Euphorbiaceae, Caesalpinaceae e Mimosaceae, predominando também as cactáceas e bromeliáceas (Andrade-Lima 1989). De acordo com a classificação de Köppen, o clima da área se enquadra no tipo BSwh', definido como semi-árido (chuva anual menor de $750 \mathrm{~mm}$ ), sem excesso hídrico. A umidade relativa é de $60,0 \%$, com precipitação média anual de $566,5 \mathrm{~mm}$. A estação chuvosa ocorre no período de novembro a abril e a estação seca ocorre no período de maio a outubro (Fonte: Centro de Pesquisa Agropecuária do Trópico do Semi-Árido - EMBRAPA/Petrolina, localizado a $30 \mathrm{~km}$ da área de estudo).

Jacquemontia multiflora ocorre por toda área de estudo, sendo observada com mais freqüência em locais abertos e nas bordas da caatinga. Os indivíduos são encontrados sobre arbustos e arvoretas nativas, como também sobre cercas. Por ser uma liana volúvel, cada emaranhado foi considerado como sendo um indivíduo.

Os trabalhos de campo foram desenvolvidos no intervalo de março de 1995 a julho de 1997, abrangendo horários entre 5:00 e 15:00 h, envolvendo 20 indivíduos de Jacquemontia multiflora. Para o estudo da fenologia, os indivíduos marcados foram observados semanalmente ao longo de todo ciclo, anotando-se a presença ou ausência de cada fenofase. A espécie foi considerada no pico de uma determinada fenofase quando mais de $50 \%$ dos indivíduos encontravam-se na mesma fenofase. Observações da biologia floral foram feitas ao longo de toda floração. Quanto a morfologia, as flores foram coletadas e mensuradas para verificar o comprimento e diâmetro da corola, bem como o tamanho das estruturas reprodutivas e a posição no interior da flor. Para verificar o volume e a concentração de néctar floral, botões em pré-antese foram cobertos com sacos de papel impermeável. As flores foram coletadas no final da tarde, quando foi medido, com auxílio de seringa graduada, o volume total de néctar produzido por flor. A concentração de açúcar do néctar foi medida com auxílio de refratômetro manual Atago N1 (0-32\%) . Para verificar a viabilidade dos grãos de pólen, lâminas com as anteras foram preparadas com carmim acético 1,2\% (Radford et al. 1974) e cerca de 100 grãos de pólen foram analisados por lâmina. A receptividade do estigma foi testada com Sudam III (Johansen 1940). Os visitantes foram observados ao longo de todo o período de floração, entre 5:00 e 15:00 h, sendo anotadas a frequência, duração e horário de suas visitas, bem como o comportamento dos visitantes mais freqüentes. Para cada período (ex. 5:00-6:00 h), foram feitas no mínimo cinco observações em dias não consecutivos, totalizando $46 \mathrm{~h}$ de observação.

Para determinar a estratégia reprodutiva da espécie, flores foram submetidas aos experimentos de autopolinização espontânea, autopolinização manual, agamospermia, e polinização cruzada, bem como observadas para estimar o sucesso da polinização em condições naturais. Para cada tratamento cerca de 30 flores, previamente ensacadas, e emasculadas quando necessário, foram utilizadas. O pólen usado em todos os testes foi obtido de flores ensacadas. A observação do crescimento de tubos políni$\cos$ foi feita em flores previamente submetidas a autopolinizações manuais e polinizações cruzadas em intervalos de tempo regulares $(5,10,24$ e 48 h). Esses pistilos foram submetidos à técnica de coloração de Martin (1959), e observados sob microscopia de fluorescência. Sementes obtidas em condições naturais e nos experimentos de polinização foram usadas nos testes de germinação, realizadas em placas de Petri umedecidas com água destilada. Materiais testemunho foram depositados nos Herbários da Unicamp (UEC 90.766) e da UNESP de São José do Rio Preto (SJRP 10.250).

\section{Resultados e Discussão}

Os indivíduos observados $(\mathrm{n}=20)$ mostram hábito trepador, usando como suporte árvores, arbustos, cercas, ou então, na ausência de apoio, apresentam-se como plantas rasteiras, formando grandes emaranhados. As fenofases de brotamento e de floração da população ocorrem no período de dezembro a junho, atingindo o pico no bimestre março/abril. As fenofases de senescência e frutificação ocorrem no período março a setembro, com pico no trimestre maio/julho (figura 1). Comparando as fenofases e os dados climáticos da região, observa-se que o brotamento e a floração ocorrem principalmente ao longo da estação chuvosa, enquanto que a senescência e a frutificação ocorrem na estação seca. Esta situação sugere que a precipitação é o principal estímulo da produção de folhas e flores, ao passo que a ausência de chuvas seria o fator determinante da 


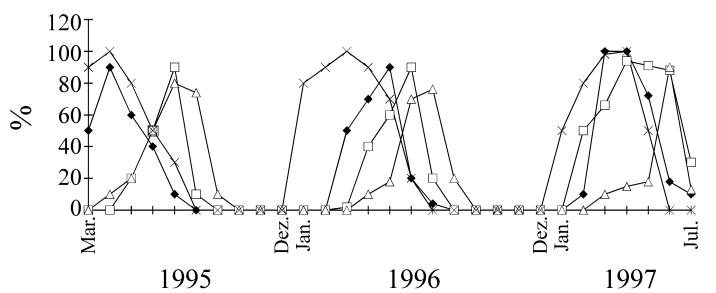

Meses do ano

Figura 1. Fenograma de Jacquemontia multiflora na Fazenda Catalunha (Santa Maria da Boa Vista - PE), durante o período de março de 1995 a julho de 1997. Floração (—-); Frutificação ( $\square-)$; Senescência ($\Delta$-); Brotamento (- $\mathrm{x}$-).

senescência e frutificação. Fato semelhante é registrado para outras espécies de Convolvulaceae (Maimoni-Rodella \& Rodella 1986, 1986/87, Piedade 1998), como também para outras espécies da caatinga (Machado et al. 1997). Quanto ao padrão de floração, esta espécie pode ser considerada como do tipo cornucópia (Gentry 1974) por apresentar produção diária de muitas flores por planta, com elevada sincronia intraespecífica, em uma única estação do ano.

Jacquemontia multiflora apresenta flores reunidas em cimeiras, em média com 20 botões por inflorescência $(\mathrm{n}=15)$, não possuindo uma seqüência definida de abertura das flores, porém, em cada inflorescência ocorre a antese de uma a quatro flores por dia. A abertura de pequeno número de flores por inflorescência por dia é observado para outras convolvuláceas da caatinga (Piedade 1998), como também para convolvuláceas de outras formações vegetais (Maimoni-Rodella \& Rodella 1986/87, Machado \& Sazima 1987, Maimoni-Rodella 1991, Maimoni-Rodella \& Rodella 1992). A exteriorização das flores fora da folhagem se dá através do eixo principal da inflorescência (figura 2), que pode alcançar até $7,0 \mathrm{~cm}$. Tal estratégia de exposição é comum entre as convolvuláceas, sendo relatadas para outras espécies da família (Maimoni-Rodella \& Rodella 1986, 1986/87, Machado \& Sazima 1987, Piedade 1998). A exteriorização das inflorescências, associada com a presença de muitas inflorescências por indivíduo, aumenta a atratividade através da grande quantidade de flores disponíveis e, conseqüente- mente, da maior disponibilidade de néctar e pólen para os visitantes.

As flores de J. multifora são raso-campanuladas, permitindo que grande parte da corola possa ser utilizada como plataforma de pouso. A corola apresenta em média 15,6 mm de diâmetro e 4,2 mm de comprimento $(\mathrm{n}=20)$, é predominantemente de coloração azul celeste (tendendo para o lilás), com a porção basal e região das mesopétalas de cor branca, que funcionam como guias de néctar. $\mathrm{O}$ androceu é formado por cinco estames heterodínamos, com anteras bitecas, basifixas com deiscência rimosa (figura 3). O gineceu é formado por um ovário súpero,

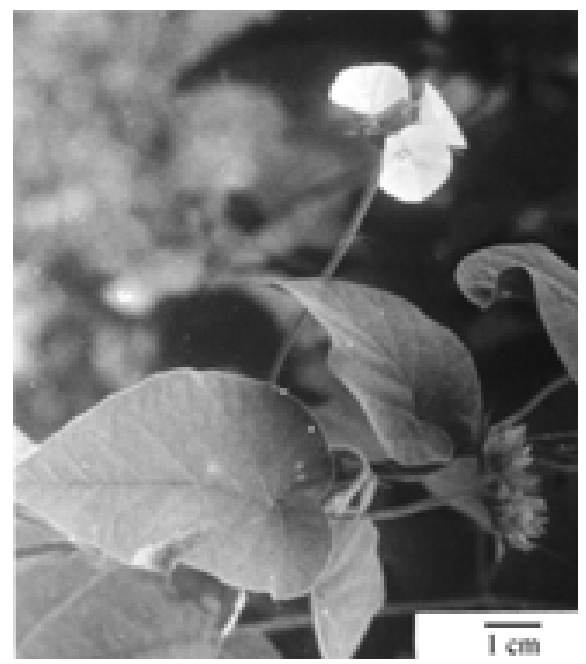

Figura 2. Jacquemontia multiflora. Note o eixo principal da inflorescência expondo as flores fora da folhagem e o número de flores abertas por inflorescência por dia.

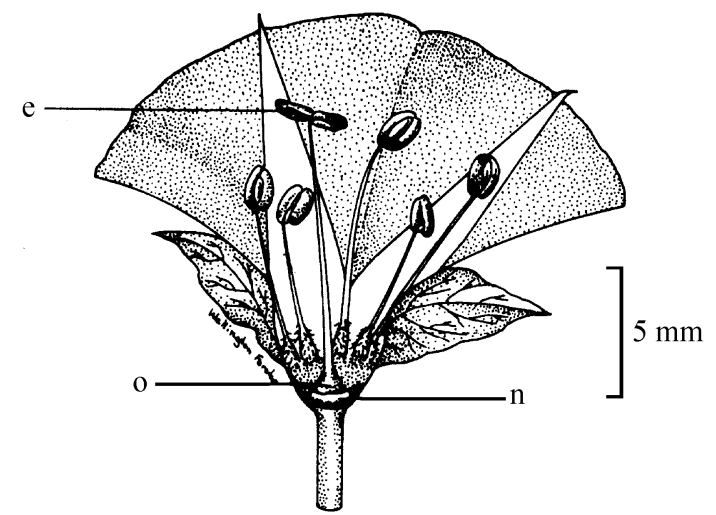

Figura 3. Jacquemontia multiflora: flor em corte longitudinal não mediano (e - estigma, $\mathrm{n}$ - nectário, o - ovário). 
bicarpelar, tetraovulado, com estiletes fundidos e estigma bilobado (figura 3). Os órgãos de reprodução são de cor branca e ficam dispostos no centro da flor, não havendo a sobreposição destas estruturas, como geralmente acontece nas convolvuláceas. O nectário se apresenta na forma de um disco hipógino (figura 3 ).

A antese das flores é diurna, começando o processo de abertura por volta de 5:30 e 6:00 h, caracterizado pelo lento afastamento das bordas da corola, que se destorcem, mostrando a prefloração imbricada torcida. Nesta fase, os grãos de pólen estão

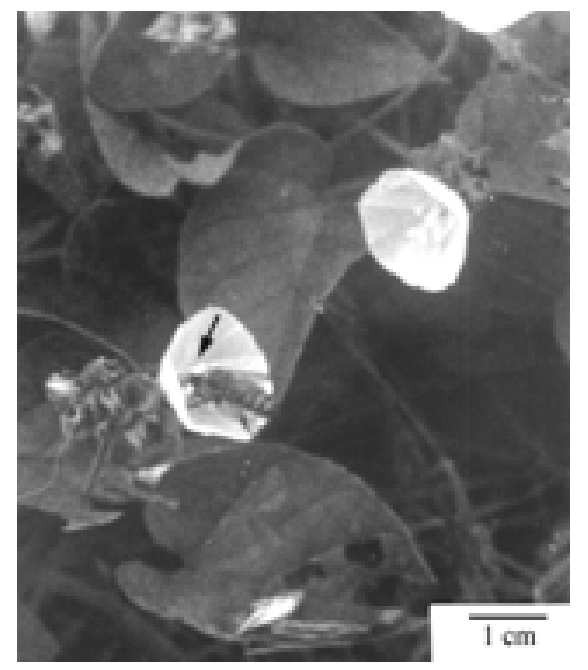

Figuras 4. Apis mellifera em visita a flor de Jacquemontia multiflora. Note estruturas reprodutivas (seta) em contato com o corpo da abelha. disponíveis nas anteras e apresentam alta viabilidade (99,6\%). O estigma está receptivo e há acúmulo de pequenas quantidades de néctar (inferiores a $1 \mu \mathrm{L}$ / flor, $\mathrm{n}=20$ ) na base da corola, o que impediu a análise de sua concentração. Assim, J. multiflora apresenta atributos florais como antese diurna, plataforma de pouso, guias de néctar e néctar abrigado na base da corola que permitem classificá-la como melitófila (Faegri \& van der Pijl 1980). As flores permanecem inalteradas até as 15:00 h, quando então se inicia o processo de senescência floral, caracterizado pelo murchamento das bordas da corola. O tempo de vida da flor é de aproximadamente nove horas, sendo consideradas como flores efêmeras (Percival 1969). Aproximadamente $24 \mathrm{~h}$ após a antese ocorre a queda dos elementos florais, exceto do cálice e ovário, se houver fecundação.

Ao longo da floração, as flores de J. multiflora são visitadas por abelhas e borboletas (tabela 1). As abelhas são os visitantes mais abundantes $(98,5 \%$ do total de visitas), e entre elas Apis mellifera é a mais abundante e a mais freqüente $(60,9 \%$ do total de visitas), visitando esta convolvulácea ao longo de todo tempo de vida da flor. Durante suas visitas, $A$. mellifera apresentou dois comportamentos distintos, um para coleta de néctar e outro para coleta de pólen. No primeiro caso, A. mellifera pousa sobre a corola, dirige-se para o centro da flor e introduz a probóscide entre as bases dos filetes para coletar o néctar. $\mathrm{Na}$ ocasião, a abelha contata anteras e estigma com a cabeça e parte dorsal do tórax (figura 4), onde o pólen é depositado, caracterizando assim a polinização no-

Tabela 1. Visitantes das flores de Jacquemontia multiflora. Ep = eficiência na polinização; Ac = Alimento coletado. (pe - polinizador efetivo, po - polinizador ocasional, pi - pilhador, n - néctar, p - pólen).

\begin{tabular}{|c|c|c|c|c|c|}
\hline $\begin{array}{l}\text { Ordem } \\
\text { Família }\end{array}$ & Espécies & Total de visitas & $\%$ & Ep & Ac \\
\hline \multicolumn{6}{|l|}{ Himenoptera } \\
\hline \multirow[t]{3}{*}{ Apidae } & Apis mellifera $\mathrm{L}$. & 599 & 60,9 & pe & $\mathrm{n}, \mathrm{p}$ \\
\hline & Trigona spinipes Fab. & 189 & 19,2 & pe & $\mathrm{n}, \mathrm{p}$ \\
\hline & Partamona sp. & 36 & 3,7 & pi & $\mathrm{n}$ \\
\hline Halictidae & Augochlora sp. & 145 & 14,7 & po & $\mathrm{p}$ \\
\hline \multicolumn{6}{|l|}{ Lepidoptera } \\
\hline Pieridae & Ascia monuste L. & 15 & 1,5 & pi & $\mathrm{n}$ \\
\hline Total & & 984 & 100,0 & & \\
\hline
\end{tabular}


totríbica. Para coleta de pólen, esta abelha pousa sobre as estruturas reprodutivas e, com o auxílio das pernas anteriores, coleta os grãos de pólen. Durante a coleta, a abelha contata as estruturas reprodutivas com a parte ventral do corpo, onde o pólen é depositado, caracterizando a polinização esternotribica. Apesar de A. mellifera ter sido a espécie mais freqüente e um eficiente polinizador, esta abelha é introduzida, não sendo um polinizador natural desta Convolvulaceae.

Trigona spinipes e Partamona sp. apresentaram comportamento de coleta de néctar semelhante ao descrito acima, porém somente a primeira contata as estruturas reprodutivas, podendo ser considerada como polinizador efetivo de $J$. multiflora na ausência de $A$. mellifera, enquanto que a segunda é considerada como pilhador de néctar. Augochlora sp. apresentou comportamento de coleta de pólen semelhante ao descrito para A. mellifera, contatando as estruturas reprodutivas com parte ventral do corpo, sendo considerada como polinizador ocasional desta Convolvulaceae. A borboleta Ascia monuste visita as flores em busca de néctar, porém não contata as estruturas reprodutivas, sendo então considerada como pilhador de néctar. Jacquemontia multiflora seria considerada como uma espécie oligofilica (Faegri \& van der Pijl 1980), e de acordo com o número de abelhas que foram observadas realizando a polinização, pode ser classificada como um espécie melitófila de polinização promíscua (Percival 1969), uma vez que os visitantes têm fácil acesso aos recursos florais.

Outras espécies da família Convolvulaceae, pertencentes aos gêneros Merremia e Ipomoea, estudadas no Brasil, são visitadas principalmente por abelhas das famílias Anthophoridae, Apidae e Halic- tidae. Entre as Apidae, Apis mellifera e Trigona spinipes são consideradas como polinizadores efetivos e/ou ocasionais de Merremia cissoides e $M$. dissecta, Ipomoea acuminata, I. cairica e I. aristolochiaefolia (Maimoni-Rodella et al. 1982, Maimoni-Rodella \& Rodella 1986, MaimoniRodella 1991, Maimoni-Rodella \& Rodella 1986/87 e Maimoni-Rodella \& Rodella 1992). Para as Convolvulaceae da caatinga, as abelhas predominam como agentes polinizadores, sendo A. mellifera e Diadasina riparia os polinizadores mais freqüentes em sete espécies observadas (Piedade 1998). Machado (1990) também considera as abelhas como polinizadores efetivos em 77,4\% dos taxóns estudados da caatinga, sendo A. mellifera e $T$. spinipes as espécies mais expressivas. Verifica-se que as abelhas Apidae desempenham importante papel na polinização das Convolvulaceae e em outras plantas da caatinga.

Os experimentos de polinização sugerem que Jacquemontia multiflora é autocompatível, formando frutos a partir de autopolinização (tabela 2). As diferenças encontradas entre os experimentos de autopolinização espontânea (3\%) e manual (30\%), sugerem maior eficiência no segundo. Esta diferença pode ser decorrente da própria morfologia floral, uma vez que, as flores por serem raso-campanuladas, permitem que as anteras fiquem distribuídas a certa distância do estilete/estigma, o que dificulta o contato do pólen com o próprio estigma e implica na necessidade de um polinizador. As maiores taxas de frutificação são registradas nos experimentos de polinização cruzada e em condições naturais, não sendo verificadas diferenças entre os dois tratamentos. No entanto, seria esperado que a frutificação em condições naturais apresentasse porcentagens menores,

Tabela 2. Resultados dos experimentos de polinização e da germinação das sementes de Jacquemontia multiflora, na Fazenda Catalunha, Santa Maria da Boa Vista - PE. $\mathrm{N}_{1}=$ total de sementes, $\mathrm{N}_{2}=$ sementes germinadas, $\%$ - porcentagem de sucesso.

\begin{tabular}{lcccc}
\hline Experimentos de polinização & Flores/frutos & $\%$ & $\mathrm{~N}_{1} / \mathrm{N}_{2}$ & $\%$ \\
\hline Condições maturais & $31 / 19$ & 60 & $15 / 15$ & 100 \\
Autopolinização espontânea & $30 / 01$ & 03 & $03 / 0$ & 0 \\
Autopolinização manual & $30 / 10$ & 33 & $15 / 14$ & - \\
Apomixia & $30 / 0$ & 00 & $15 / 14$ & - \\
Polinização cruzada & $30 / 18$ & 60 & 93 \\
\hline
\end{tabular}


pois os frutos assim formados podem ser decorrentes de autopolinização ou de polinização cruzada. Os frutos resultantes de polinização cruzada, por sua vez, deveriam apresentar taxas maiores, porque nas flores manualmente polinizadas houve suficiente deposição de pólen sobre o estigma. Porém, a manipulação dos botões florais durante a emasculação, associada ao fato da elevação da temperatura (acima de $40{ }^{\circ} \mathrm{C}$ ) dentro do saco de papel usado como envoltório protetor, poderiam ter influenciado negativamente a frutificação. Frutos apomíticos não foram observados. A análise estatística $\left(X^{2}\right)$ indica que há diferenças significativas entre os tratamentos, ao nível de 5\%, quando se compara a frutificação obtida em condições naturais e autopolinização manual $\left(X^{2}=4,82 ; \mathrm{p}=0,0281\right)$, e autopolinização manual e polinização cruzada $\left(X^{2}=4,28 ; \mathrm{p}=0,0386\right)$, indicando que, embora seja autocompatível, a espécie tem mais sucesso com a xenogamia, que mantém os níveis de variabilidade genética na população.

Com relação aos testes de crescimento de tubo polínico, nenhuma diferença em relação a velocidade de crescimento foi observada em nível de estigma e estilete, nos dois tratamentos. Após cinco horas, há tubos polínicos na região do ovário e, após dez horas, observa-se tubos polínicos na micrópila de óvulos submetidos tanto à autopolinização como à de polinização cruzada. Na família Convolvulaceae, sistemas de autoincompatibilidade estão amplamente distribuídos pelo gênero Ipomoea, sendo que, na maioria dos casos, os sistemas são do tipo esporofítico (Martin 1970). Porém, estudos reprodutivos feitos no Brasil registram espécies autocompatíveis para os gêneros Merremia e Ipomoea (Maimoni-Rodella et al. 1982, Maimoni-Rodella \& Rodella 1986, 1986/87, Machado \& Sazima 1987, Maimoni-Rodella 1991, Maimoni-Rodella \& Rodella 1992, Piedade 1998), indicando que autocompatibilidade ocorre com freqüência na família.

O fruto de Jacquemontia multiflora é uma cápsula loculicida, formada por quatro lóculos, cada um com uma semente. Os frutos são pequenos, arredondados (4 mm de comprimento x $3 \mathrm{~mm}$ de largura, $\mathrm{n}=15$ ) e apresentam coloração paleácea. A análise dos frutos obtidos em condições naturais e nos experimentos de polinização mostram que há formação de três a quatro sementes por fruto e que o tamanho da semente varia de acordo com a quantidade de sementes formadas. Esta variação no tamanho da semente é relatada por Groth (1991) para várias espécies de Convolvulaceae, assim como altas taxas de produção de sementes são relatadas por Crowley \& Buchanan (1982) para J. tamnifolia. As sementes de $J$. multiflora são pequenas (ca. de 2,0 $\mathrm{mm}$ de diâmetro) e de forma arredondada. Os testes de germinação mostraram que as sementes obtidas nos experimentos de polinização são viáveis, com altas taxas de germinação (tabela 2), reforçando os dados da literatura sobre a reprodução de espécies invasoras da família Convolvulaceae, que ocorre exclusivamente por meio de sementes (Blanco 1978, Groth 1991).

Os dados obtidos indicam que J. multiflora é autocompatível. A polinização por abelhas generalistas, como A. mellifera e T. spinipes, associada à possibilidade de autofecundação e polinização cruzada, confere a esta Convolvulaceae adaptação adequada a plantas daninhas e invasoras de culturas. Assim, J. multiflora apresenta características que permitem classificá-la como uma "planta invasora ideal" (Baker 1974), pois além da autocompatibilidade, apresenta altas taxas de frutificação e produção de sementes/fruto, bem como altas taxas de germinação.

Agradecimentos: À Dra. Rosângela Simão-Bianchini (Instituto de Botânica - São Paulo) pela identificação do material botânico, ao Prof. Dr. João F.M. Camargo (USPRibeirão Preto) pela identificação das abelhas, e ao CNPq pelo auxílio financeiro.

\section{Referências bibliográficas}

ANDRADE-LIMA, D. 1989. Plantas das Caatingas. Academia Brasileira de Ciências, Rio de Janeiro.

AUSTIN, D.F. 1975. Convolvulaceae. In Flora of Panamá. Annals of Missouri Botanical Garden 62:157-224.

BAKER, H.G. 1974. The evolution of weeds. Annual Review of Ecology and Systematics 5:1-24.

BLANCO, H.G. 1978. Catálogo das espécies de mato infestantes de áreas cultivadas no Brasil. Família das Campainhas (Convolvulaceae). O Biológico 44:259278.

CROWLEY, R.H. \& BUCHANAN, G.A. 1982. Variations in seed production and the response to pests of morningglory (Ipomoea) species and smallflower morninglory (Jacquemontia tamnifolia). Weed Science 30:187-190. 
FAEGRI, K. \& van der PIJL, L. 1980. The principles of pollination ecology. Pergamon Press. Oxford-New York.

GENTRY, A.H. 1974. Flowering phenology and diversity in tropical Bignoniaceae. Biotropica 6:64-68.

GROTH, D. 1991. Morphological characterization of seeds and seedlings of seven weed species of Convolvulaceae occuring in agricultural seeds in Brazil. Iheringia 41:83-99.

JOHANSEN, D.A. 1940. Plant microtechnique. McGrawHill Book Company, New York.

KISSMAN, K.G. \& GROTH, D. 1992. Plantas infestantes e nocivas. Basf. São Paulo. Tomo II.

MACHADO, I.C.S. 1990. Biologia floral de espécies da caatinga no município de Alagoinha (PE). Tese de doutorado, Universidade Estadual de Campinas.

MACHADO, I.C.S. \& SAZIMA, M. 1987. Estudo comparativo da biologia floral em duas espécies invasoras: Ipomoea hederifolia e I. quamoclit (Convolvulaceae). Revista Brasileira de Biologia 47:425-436.

MACHADO, I.C.S., SANTOS, L.M. \& SAMPAIO, E.V.S.B. 1997. Phenology of caatinga species at Serra Talhada, PE, northeastern Brazil. Biotropica 29:57-68.

MAIMONI-RODELLA, R.C.S. 1991. Biologia floral de Ipomoea aristolochiaefolia (H.B.K) Don. (Convolvulaceae). Turrialba 41:344-349.
MAIMONI-RODELLA, R.C.S. \& RODELLA, R.A. 1986. Aspectos da biologia floral de Merremia dissecta (Jacq.) Hall. f. var. edentata (Meissn.) O'Donell (Convolvulaceae). Revista de Agricultura 61:213-222.

MAIMONI-RODELLA, R.C.S. \& RODELLA, R.A. 1986/87. Biologia floral de Merremia cissoides (Lam.) Hall F. (Convolvulaceae). Naturalia 11/12:117-123.

MAIMONI-RODELLA, R.C.S. \& RODELLA, R.A 1992. Biologia floral de Ipomoea acuminata Roem. Et Schult. (Convolvulaceae). Revista Brasileira de Botânica 15:129-133.

MAIMONI-RODELLA, R.C.S., RODELLA, R.A., AMARAL JUNIOR, A. YANAGIZAWA, Y. 1982. Polinização em Ipomoea cairica (L.) Sweet. (Convolvulaceae). Naturalia 7:167-172.

MARTIN, F.W. 1959. Staining and observing pollen tubes in the style by means of fluorescence. Stain Technology 37:125.

MARTIN, F.W. 1970. Self- and interespecific incomaptibility in the Convolvulaceae. Botanica Gazette 131:130-144.

PERCIVAL, M.S. 1969. Floral Biology. Pergamon Press, London.

PIEDADE, L.H. 1998. Biologia da polinização e reprodutiva de sete espécies de Convolvulaceae na caatinga do Sertão de Pernambuco. Tese de doutorado, Universidade Estadual de Campinas.

RADFORD, A.E., DICKDON, W.C., MASSEY, J.R. \& BELL, C.R. 1974. Vascular plant systematics. Harper and Row Publ., New York. 